\title{
Analysis and Design of Colpitts Oscillator for Short-range WSN
}

\author{
Mousa Yousefi
}

\begin{abstract}
In this paper, analysis and design of colpitts oscillator with ability to transmit data at low output power with application in short-range wireless sensor networks such as MICS is described. Reducing the area required to implement the transmitter, on-chip implementation and appropriate energy efficiency are the advantages of this structure that makes it suitable for the design of short-range transmitter in biomedical applications. The proposed OOK transmitter works at $405 \mathrm{MHz}$ with 10 Mbps data rate. Output power and total power consumption are $25 \mu \mathrm{W}$ and $726 \mu \mathrm{W}$, respectively. Energy efficiency is $72.6 \mathrm{pJ} / \mathrm{bit}$. The transmitter has been designed and simulated in $0.18 \mu \mathrm{m}$ CMOS technology.
\end{abstract}

Keywords-Short-range wireless sensor networks, Colpitts oscillator, High efficiency, Transmitter

\section{INTRODUCTION}

W ireless body sensor networks (WBSN) connect several sensors with applications like monitoring vital body signals, diagnosis of illnesses and drug delivery. Local or private networks or world-wide web are used to connect this sensor networks to health-care and emergency centers. Fig. 1 shows a conceptual view of this communication and wireless body sensor network (WBSN) applications [1]-[5]. In WBSN, the distance between the sensor node and central node is less than $3 \mathrm{~m}$. For these distances, the power needed for the transmitter should be about $1 \mathrm{~mW}$. Generally, a sensor node comprises the sensor, analog to digital converter, microprocessor and the transceiver. A sensor node must occupy a very small area so the required circuit must be designed with the area as small as possible.

Wireless nature of these networks and area limitation make the applications energy-limited. Because the major part of power is consumed by the transceiver, a proper transceiver design is a challenge for researchers and designers in this field.

Because these networks operate in short ranges, high output power is not needed for data transmission. For example, in short-range wireless sensor networks such as ZigBee, the required output power is $1 \mathrm{~mW}$ [6] and for MICS1 is $25 \mu \mathrm{W}$ [7].

The most important parameter in design of the transceiver in short-range wireless sensor network is the amount of energy used for the transmission of correct data. To evaluate this property, Figure of Merit (FOM) is used which is calculated by Equation 1.

This work was supported by Department of Electrical Engineering, Faculty of Engineering, Azarbaijan Shahid Madani University, Tabriz, IRAN.

Author is with Mousa Yousefi (Department of Electrical Engineering, Faculty of Engineering, Azarbaijan Shahid Madani University, Tabriz, IRAN (e-mail:m.yousefi@azaruniv.edu).

$$
F O M_{T x}=P_{D C} / D R
$$

Where $\mathrm{P}_{\mathrm{DC}}$ is power dissipation and $\mathrm{DR}$ is data rate of transmitter. As Equation 1 states, to improve the performance of the transmitter ,power consumption must be reduced. On the other hand, higher data rates improve FOM. According to (1), choosing the modulation method is effective in increasing the data rate and decreasing the consumed power. For example, OOK modulation requires simpler structure compared to other methods like FSK or PSK which results in reduced power consumption. But it has poor interference and noise performance in comparison to FSK and PSK. In overall, OOK has more popularity [8]-[9].

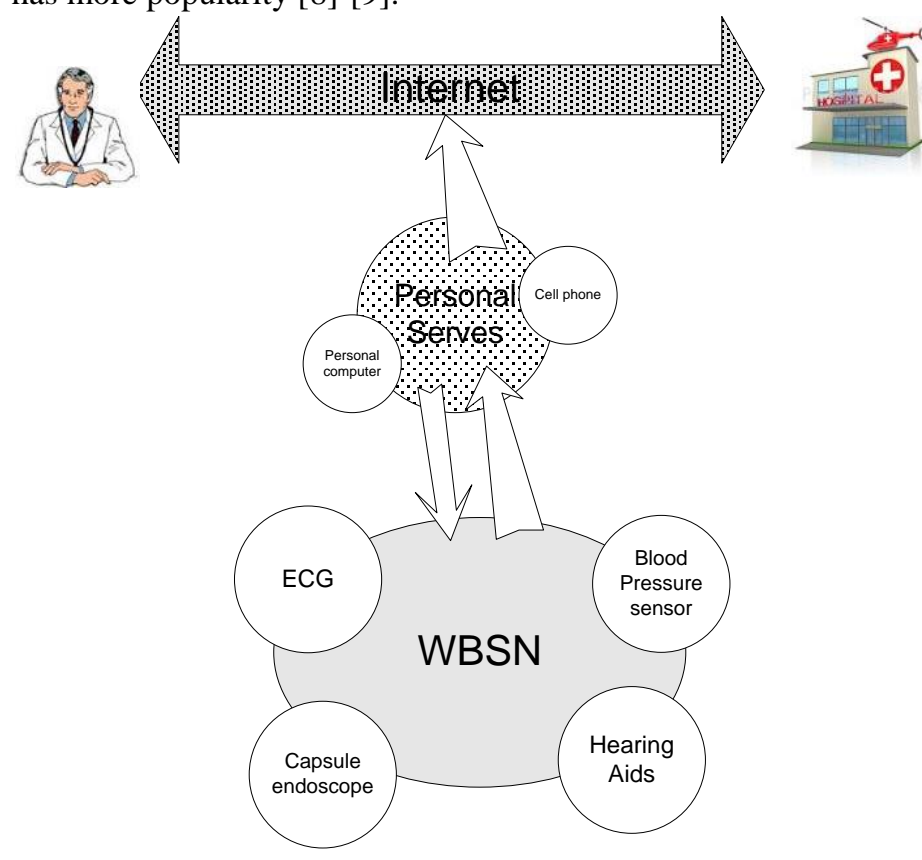

Fig. 1. Communication in WBSN

Considering the structure of different transmitters, it can be concluded that signal generator and power amplifier are two building blocks of transmitter. So, these two blocks must be low power. The task of the oscillator is to generate a carrier signal with proper frequency tuning, low power consumption and low voltage operation. On the other hand, the power amplifier provides the power needed for the transmitter and must have appropriate power efficiency. In short-range wireless sensor network, high output power is not needed. For example, MICS needs output power about $25 \mu \mathrm{W}$. In this paper, analysis and design flow of a Colpitts oscillator with low output power data transmission capability has been presented. This structure does not need a power amplifier 
which decreases the area and improves the efficiency of the transmitter. In Section II, the structure of Colpitts oscillator and the equation governing its behavior are discussed. Section III provide the design flow for the oscillator with the ability for low output power data transmission. In Section IV, results obtained from the design of a transmitter with low output power based on equations and design flow mentioned in Sections 2 and 3 are provided. Section V concludes the paper.

\section{EQUATION GOVERNING COLPITTS OSCILLATOR}

The structure of Colpitts oscillator has been shown in Fig. 2. It is formed by the inductor $\mathrm{L}$, and the capacitances $\mathrm{C} 1$ and $\mathrm{C} 2$ which provide a feedback path. The inductor loss of the tank circuit is compensated by the transistor gain.

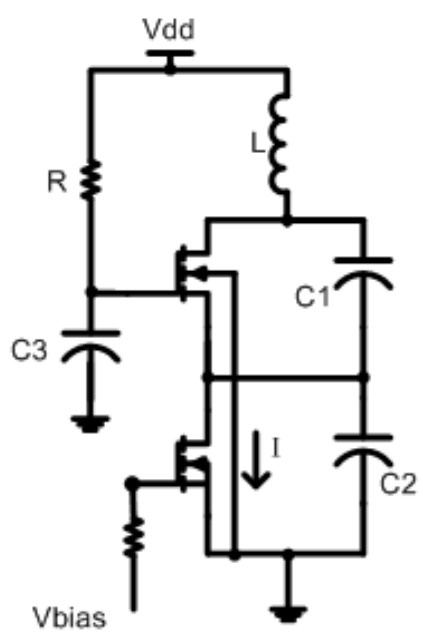

Fig. 2. Colpitts oscillator

To control the oscillating condition, we can control the loop gain and be sure that for 0 degree phase shift, loop gain is higher than unity or calculate the equivalent resistance of the tank and cancel it with the negative resistance achieved by active device. In first approach, which is the Barkhausen criterion the gain of the main amplifier is equal to the transconductance multiplied by the load impedance. The load impedance is the parallel combination of the inductor with a capacitance equal to the series of two capacitances $\mathrm{C}_{1}$ and $\mathrm{C}_{2}$. The amount of feedback can be calculated from the proportion between $\mathrm{C}_{1}$ and $\mathrm{C}_{2}$. Using these values and satisfying oscillating condition, the minimum gm can be calculated [7]. This minimum value is specified by the loss of the inductor and oscillating conditions. The loss of LC circuit is strongly dependent on their quality factor. On-chip inductors have low quality factors $(4 \sim 6)$ while off-chip counterparts provide higher quality factors. Furthermore, since oscillator has large output amplitude applied to the amplifier using the feedback path, its calculations must be carried out with large signal behavior in mind. Squegging effect reduces the feedback coefficient $(\beta=0.3)$. It can be shown that $[10]$ the minimum $\mathrm{gm}$ is equal to:

$$
\begin{aligned}
& g_{m, \min }=\frac{1}{R .(1-n)} \\
& n=C_{1} /\left(C_{1}+C_{2}\right)
\end{aligned}
$$

where $\mathrm{R}$ represents the loss of the inductor. Considering the equation, to increase the transconductance, $\mathrm{R}$ should be minimized meaning that the loss of the inductor and capacitances must be minimized. In other words, these elements must have high quality factors. With a short description about Colpitts oscillator, equations needed by the designer for an oscillator with the ability to transmit data at low output power level will be discussed in the following section. More details could be found in the references.

\section{OSCILlAtor Design With DATA TRANSMISSION ABILITY}

Fig. 4 shows Colpitts oscillator with the ability to transmit power at low output power level without the need for a power amplifier. Minimum operating voltage for this structure is:

$$
V_{D D, \text { min }}=V_{d s}+V_{G S}=V_{d s, s a t}+V_{T H}
$$

In this structure, the capacitor $\mathrm{Cc}$ is used to separate DC signal form the antenna and $\mathrm{C}_{\mathrm{p}}$ is the parasitic capacitance of that node. There are 7 unknown variables for the design: Capacitors $\mathrm{C}_{1}, \mathrm{C}_{2}, \mathrm{C}_{\mathrm{p}}$ and $\mathrm{C}_{\mathrm{c}}$, inductor $\mathrm{L}$, operating voltage, size of the transistor $\mathrm{M} 1$ and the current consumed by the oscillator. For this design, the output power, oscillation frequency and the load (50 $\Omega$ resistance of the antenna) are considered to be known values.

$$
\omega_{0}=\frac{1}{\sqrt{L C_{T}}}
$$

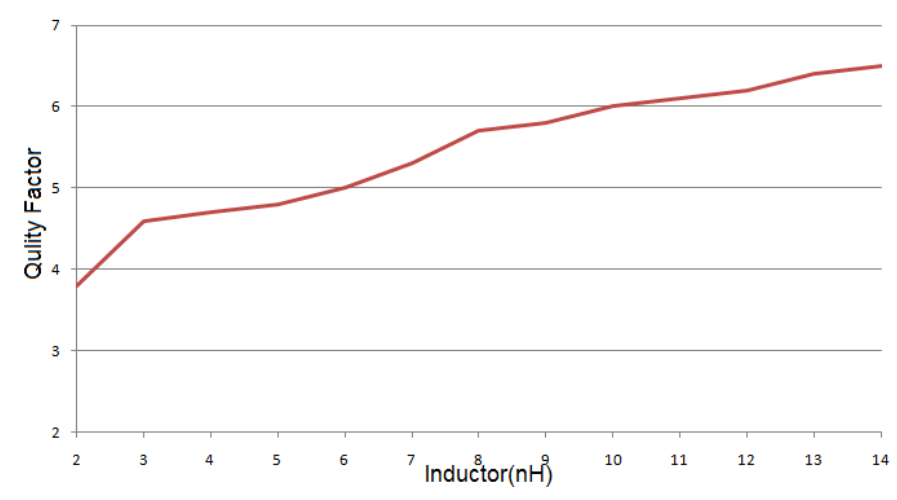

Fig. 3. Quality factor versus the value of the inductor in $0.18 \mu \mathrm{m}$ at $400 \mathrm{MHz}$

Choosing the value of on-chip inductor is important because on-chip inductors have higher losses. Fig. 3 shows the quality factor versus the value of inductor in $0.18 \mu \mathrm{m}$ at $400 \mathrm{MHz}$. The value of inductor is chosen using this curve. Then, Equation 5 is used to obtain the value of the equivalent capacitor $C_{T}$. The value of the equivalent capacitor $C_{T}$ is determined by

$$
C_{T} ; C_{e q}+C_{c p}
$$

In this equation, capacitance $\mathrm{C}_{\mathrm{eq}}$ is the equivalent of $\mathrm{C}_{1}$ and $\mathrm{C}_{2}$ and capacitance $\mathrm{C}_{\mathrm{cp}}$ is the equivalent of $\mathrm{C}_{\mathrm{p}}$ and $\mathrm{C}_{\mathrm{c}}$. The value of $C_{p}$ parallel with the antenna can be calculated with a good approximation. Impedance of $C_{p}$ is considered to be larger than the resistance of the antenna and in this condition $\mathrm{C}_{\mathrm{p}}$ is calculated. By using the equation in Appendix and converting the parallel capacitance-resistance to series equivalent, the value of series resistor and capacitor can be 
calculated. The obtained capacitor value is in series with $\mathrm{C}_{\mathrm{c}}$. This series combination can be converted to parallel equivalent, again. Finally, the equivalent circuit of parallel resistor-capacitor $\mathrm{C}_{\mathrm{cp}}$ can be added to node $\mathrm{V}_{\mathrm{D}}$.

The transistor current can be calculated to satisfy oscillating conditions in Equation 2. The voltage amplitude at node $\mathrm{Vd}$ can be obtained by using Equation 6. The output voltage amplitude is calculated using Equation 7. The output impedance can be obtained by using the output current Im. The value of capacitor $\mathrm{C}_{\mathrm{sp}}$ can be achieved by Equation 8 .

$$
\begin{gathered}
V_{\text {out }}=2 I_{\text {bias }} R(1-n) \\
Z_{\text {out }}=\frac{\left|V_{\text {out }}\right|}{\left|I_{m}\right|}=\sqrt{\left(\omega C_{s p}\right)^{2}+R_{s p}^{2}}
\end{gathered}
$$

By using the $\mathrm{C}_{\mathrm{sp}}, \mathrm{C}_{\mathrm{cp}}$ can be obtained and $\mathrm{C}_{\mathrm{eq}}$ can be obtained by Equation 6. Equation 3, 6 and 8 can be used to calculated $\mathrm{C}_{1}$ and $\mathrm{C}_{2}$.

$$
C_{e q}=C_{1} C_{2} /\left(C_{1}+C_{2}\right)
$$

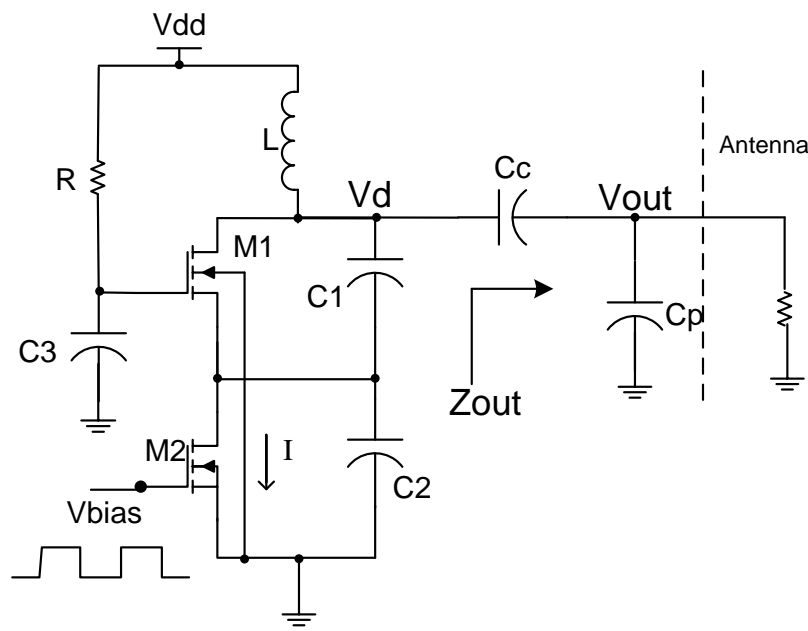

Fig. 4. Transmitter circuit based on Colpitts oscillator

\section{Simulation Results}

Considering the structure of Colpitts oscillator, its equation and design procedure the calculated values for $0.18 \mu \mathrm{m}$ technology are summarized in Table I. These values are optimized by the simulations.

By using this design, output power level and power consumption in active time are obtained. It has been used for the design of a transmitter working at $405 \mathrm{MHz}$ with $10 \mathrm{Mbps}$ data rate and output power $-16 \mathrm{dBm}$ with $\mathrm{OOK}$ modulation ( $V_{\text {bias }}$ is shown in Fig.4, is used for modulation OOK) . Fig. 5 shows the output voltage for 1010 data pattern. Fig. 6 shows the phase noise of the proposed transmitter which has -126 $\mathrm{dB} / \mathrm{Hz}$ phase noise. Table II shows the important parameters of the proposed transmitter. Also, in this table, parameters of other transmitters have been provided. In fact, this transmitter is suitable for the transmitter part in MICS sensor networks. Smaller area and improved FOM are the advantages of the proposed transmitter. Also, all of its parts can be integrated fully on-chip. In this table, transmitter of [11] is low power but it uses off-chip elements. In proposed transmitter by using offchip elements, power consumption can be reduced and proper energy efficiency can be achieved. Reference [2], has higher operating voltage which results in higher power consumption and improper energy efficiency. Fig. 7 is shown layout of proposed oscillator.

TABLE 1

Calculated Values for the Proposed Transmitter

\begin{tabular}{|c|c|c|c|c|c|c|c|}
\hline & $\mathrm{L}$ & $\mathrm{C} 1$ & $\mathrm{C} 2$ & $\mathrm{Cc}$ & $(\mathrm{W} / \mathrm{L})_{\mathrm{M} 1}$ & $(\mathrm{~W} / \mathrm{L})_{\mathrm{M} 2}$ & $\mathrm{VDD}$ \\
\hline Value & 12 & 16.2 & 24 & 2 & 900 & 660 & 0.6 \\
\hline Unit & $\mathrm{nH}$ & $\mathrm{pF}$ & $\mathrm{pF}$ & $\mathrm{pF}$ & --- & --- & $\mathrm{V}$ \\
\hline
\end{tabular}

\section{CONCLUSION}

Analysis and design of Colpitts oscillator with ability to transmit data at low output power level with application in short-range wireless sensor networks like MICS has been presented. The proposed transmitter which employs OOK modulation works at $405 \mathrm{MHz}$ with $10 \mathrm{Mbps}$ data rate. Output power is $25 \mu \mathrm{W}$ and total power consumption is $726 \mu \mathrm{W}$. Energy efficiency is $72.6 \mathrm{pJ} / \mathrm{bit}$. An advantage of this structure is the possibility of full integration on chip. The whole transmitter has been designed and simulated in $0.18 \mu \mathrm{m}$ CMOS technology.

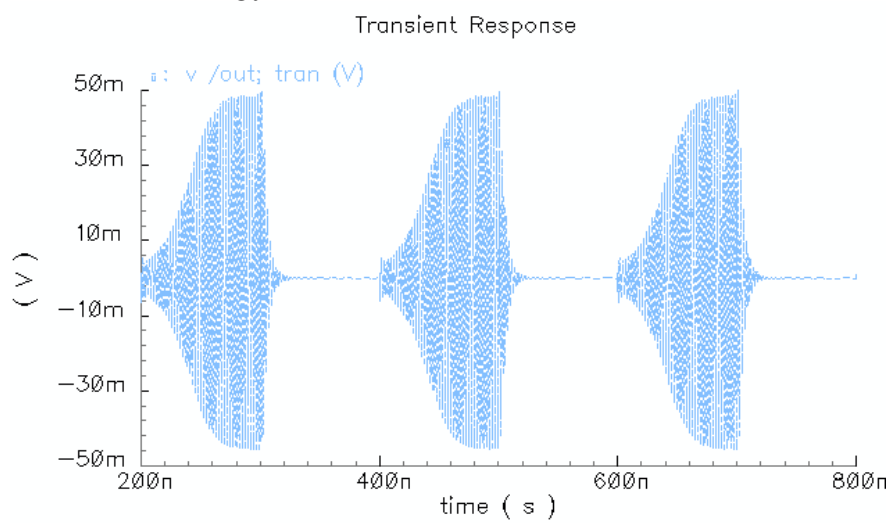

Fig. 5. Transmitter output with 1010 transmission pattern

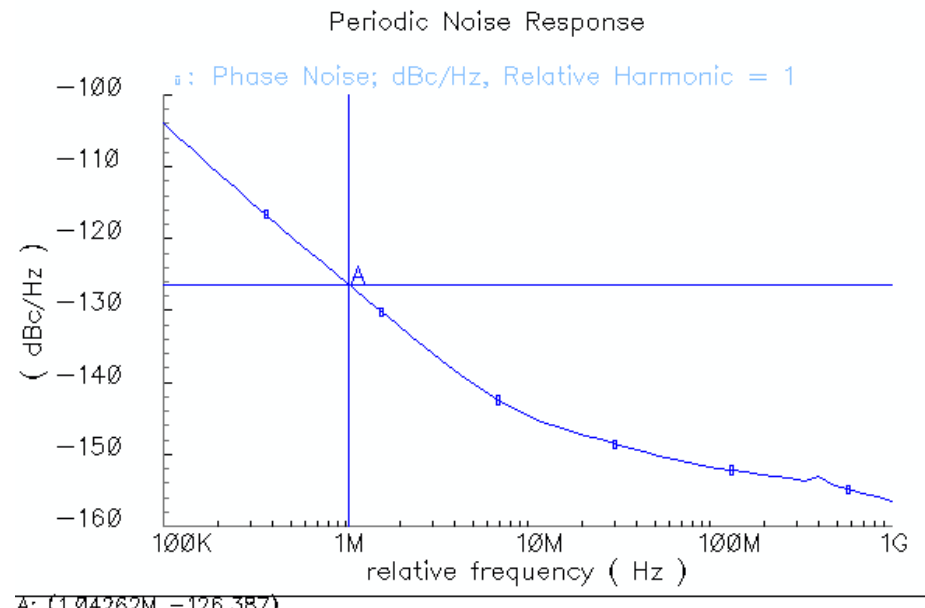

A: $(1.04262 \mathrm{M}-126.387)$

Fig. 6. Phase noise of the proposed transmitter based on Colpitts oscillator 


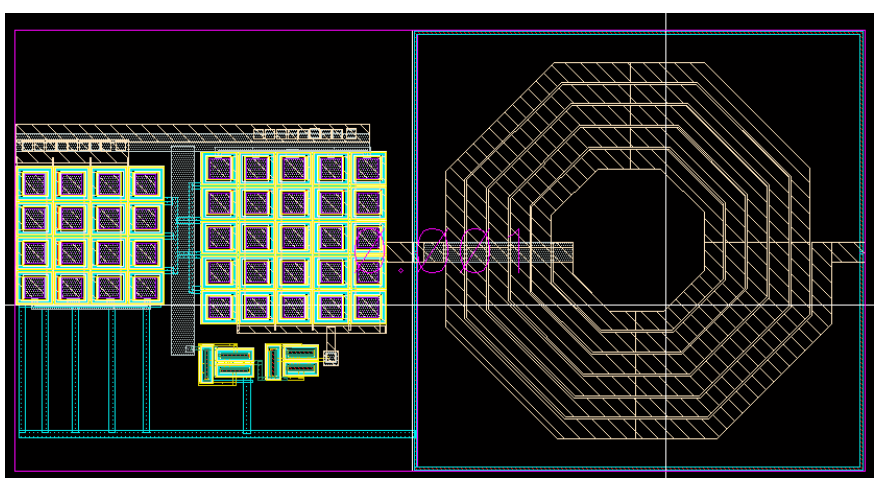

Fig. 7. Layout of Osillator

TABLE II

IMPORTANT PARAMETERS OF THE PROPOSED TRANSMITTER AND COMPARISON

\begin{tabular}{|c|c|c|c|c|c|c|}
\hline Ref. & $\begin{array}{c}\text { Freq. } \\
(\mathrm{MHz})\end{array}$ & $\begin{array}{c}\text { Tech. } \\
(\mu \mathrm{m})\end{array}$ & $\begin{array}{c}\text { DR } \\
(\mathrm{Mbps})\end{array}$ & Mod. & $\begin{array}{c}\mathrm{P}_{\text {out }} \\
(\mathrm{dBm})\end{array}$ & $\begin{array}{c}\text { FOM } \\
(\mathrm{nJ} / \mathrm{bit})\end{array}$ \\
\hline $\begin{array}{c}\text { Prop TX } \\
\text { (Simulated) }\end{array}$ & 405 & 0.18 & 10 & OOK & -16 & 0.0726 \\
\hline$[11]$ & 433 & 0.35 & 10 & OOK & -10 & 0.0518 \\
\hline$[2]$ & 440 & 0.35 & 40 & OOK & 0 & 68 \\
\hline
\end{tabular}

\section{APPENDIX A}

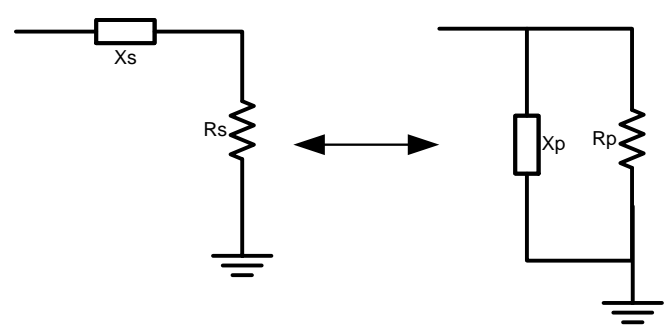

Fig. 8. Series to parallel and parallel to series conversions

Relationships governing these conversions are described by the following equations (see Fig. 8).

$$
\begin{gathered}
X_{p}=X_{s}\left(1+Q_{s}^{2}\right) / Q_{s}^{2} \\
X_{s}=X_{p} \cdot Q_{p}^{2} /\left(1+Q_{p}^{2}\right) \\
R_{p}=R_{s}\left(1+Q_{s}^{2}\right) \\
R_{s}=R_{p} /\left(1+Q_{p}^{2}\right)
\end{gathered}
$$

\section{REFERENCES}

[1] J. P. Carmo, N. Dias, P. M. Mendes, C. Couto, Helder Raul Silva,and J. H. Correia, "A 2.4-GHz Low-Power/Low-Voltage Wireless Plug-andPlay Module for EEG Applications", IEEE Sensors Journal. 2007, vol. 11, pp. 1524-1531. doi:10.1109/JSEN.2007.908238.

[2] D. C. Daly and A. P. Chandrakasan, "An energy-efficient OOK transceiver for wireless sensor networks," IEEE J. Solid-State Circuits. 2007, vol. 42(5), pp. 1003-1011 doi: 10.1109/JSSC.2007.894323

[3] Q. Zhang , X. Kuang and N. Wu, "ultra-low-power RF transceiver for WBANs in medical applications," Journal of Semiconductors. 2011, vol. 32(6), pp. 065008. doi: 10.1109/NEWCAS.2012.6328977

[4] A. W. Wong, et al. "A 1V, micropower system-on-chip for vital-sign monitoring in wireless body sensor networks." Solid-State Circuits Conference, 2008. ISSCC 2008. Digest of Technical Papers. IEEE International. IEEE, 2008. pp. 138-602 doi: 10.1109/ISSCC.2008.4523095

[5] Y. J. Yang, et al. "A release-on-demand wireless CMOS drug delivery SoC based on electrothermal activation technique." Solid-State Circuits Conference-Digest of Technical Papers, 2009. ISSCC 2009. IEEE International. IEEE, 2009, pp. 288-289. doi: 10.1109/ISSCC.2009.4977421

[6] P. Baronti, P. Pillai, V. W. Chook, S. Chessa, A. Gotta, \& Y. F. Hu, "A survey on the state of the art and the 802.15. 4 and ZigBee standards. Computer communications", Computer communications, vol. 30(7), pp. 1655-1695, 2007, doi: 10.1016/j.comcom.2006.12.020

[7] M. R. Yuce, et al. "A MICS band wireless body sensor network." Wireless Communications and Networking Conference, 2007. WCNC 2007. IEEE, pp. 2473-2478. doi: 10.1109/WCNC.2007.461

[8] J. L. Bohorquez, A. P. Chandrakasan, \& J. L. Dawson, " A 350 W CMOS MSK transmitter and $400 \mathrm{~W}$ OOK super-regenerative receiver for medical implant communications". Solid-State Circuits, IEEE Journal of, vol. 44(4), pp. 1248-1259. doi: 10.1109/JSSC.2009.2014728

[9] J. Bae, L. Yan, \& H. J. Yoo, "A low energy injection-locked FSK transceiver with frequency-to-amplitude conversion for body sensor applications". Solid-State Circuits, IEEE Journal of, 2011, vol. 46(4), pp. 928-937. doi: 10.1109/VLSIC.2010.5560325

[10] David M. Pozar, Microwave Engineering. Second Edition, John Wiley 1998.

[11] M. K. Raja, \& Y. P. Xu,"A 52 pJ/bit OOK Transmitter with adaptable data rate", In Solid-State Circuits Conference, 2008. A-SSCC'08. IEEE Asian, pp. 341-344. doi: 10.1109/ASSCC.2008.4708797 